\title{
Vehicle flow prediction through probabilistic modeling
}

\section{Autores}

Jesús Silva, Noel Varela, Omar Bonerge Pineda Lezama, Vladimir Álvarez, Boris de la Hoz

\begin{abstract}
Within the area of wireless and mobile communications, ad hoc vehicular networks have generated the interest of different organizations, which has generated a topic of study and analysis for the increase of applications, devices, technology integration, security, standards, and quality of service in different areas (Zhu et al. in IEEE Trans Veh Technol 64(4):1607-1619, [1]) and (Tian et al. in A self-adaptive V2V communication system with DSRC, pp 1528-1532, [2]). This study on vehicle networks shows a great deal of opportunity and motivation to deepen the aspects that involve it, which have emerged due to the advance of wireless technologies, as well as research in the automotive industry. This allows the development of networks with spontaneous topologies with vehicles in constant movement in several simulations (Mir and Filali in LTE and IEEE 802.11p for vehicular networking: a performance evaluation, pp 1-15, [3]]), with reliable vehicle flows, through the share of traffic information, considering that continuous mobility is an essential characteristic of a VANET vehicle network, which can have short changes in terms of groups of vehicles in the same direction (Lokhande and Khamitkar, 9(12):30-33, [4]). The following paper uses a road scenario called VANET to obtain a predictive characterization of vehicle flow using a probabilistic model.
\end{abstract}

\section{Palabras clave}

Mobility, Probability, SPH, Vehicular flow, Markov chains, Stochastic model 